OPEN ACCESS

Edited by:

Karl Matthews,

Rutgers University, The State

University of New Jersey,

United States

Reviewed by:

Cangliang Shen

West Virginia University, United States

Marilyn Erickson,

University of Georgia, United States

*Correspondence:

Brendan A. Niemira

brendan.niemira@ars.usda.gov

Specialty section:

This article was submitted to

Agro-Food Safety,

a section of the journal

Frontiers in Sustainable Food Systems

Received: 30 April 2018

Accepted: 18 July 2018

Published: 14 August 2018

Citation:

Niemira BA, Boyd G and Sites J (2018) Cold Plasma Inactivation of

Escherichia coli 0157:H7 Biofilms.

Front. Sustain. Food Syst. 2:47.

doi: 10.3389/fsufs. 2018.00047

\section{Cold Plasma Inactivation of Escherichia coli 0157:H7 Biofilms}

\author{
Brendan A. Niemira*, Glenn Boyd and Joseph Sites \\ Food Safety and Intervention Technologies Research Unit, Eastern Regional Research Center, Agricultural Research Service, \\ United States Department of Agriculture, Wyndmoor, PA, United States
}

Pathogenic bacteria associated with biofilms on foods and food contact surfaces are a challenge to inactivate with conventional sanitizers. Cold plasma is a novel nonthermal process with potential efficacy against these pathogens. Biofilms of Escherichia coli 0157: $\mathrm{H} 7$ were grown for 24,48 , or $72 \mathrm{~h}$ on glass slides and exposed to atmospheric cold plasma, $23-48 \mathrm{kHz}$, for 5,10 , or $15 \mathrm{~s}$. Distance from emitter to biofilms was 5 or $7.5 \mathrm{~cm}$. The temperature of the process was established using infrared digital imagery. Cold plasma at $5 \mathrm{~cm}$ reduced biofilms by up to $1.41,2.57$, or $3.29 \log \mathrm{cfu} \mathrm{ml}^{-1}$ for 5 , 10 , or $15 \mathrm{~s}$, respectively. Cold plasma at $7.5 \mathrm{~cm}$ had reduced maximal efficacy at 5 and $10 \mathrm{~s}$ (0.96 and $2.13 \mathrm{log} \mathrm{cfu} \mathrm{ml}^{-1}$, respectively), but was unchanged for $15 \mathrm{~s}$ (3.29 log cfu $\mathrm{ml}^{-1}$ ). Biofilm age was not significant factor influenceing cold plasma efficacy. All treatments were confirmed to be non-thermal. Cold plasma can be a sanitizing tool for food contact surfaces.

Keywords: biofilms, cold plasma, Escherichia coli 0157:H7, nonthermal processing, food safety

\section{INTRODUCTION}

Foodborne illness resulting from contamination with bacterial pathogens remains an ongoing concern for producers and consumers (Mandrell, 2009; Cevallos-Cevallos et al., 2012; Ziuzina et al., 2014). These foods may be inoculated by food contact surfaces such as containers, conveyor belts, knives, etc. on which pathogens such as Escherichia coli O157:H7 may be resident, often as biofilms (Reisner et al., 2006; Doyle and Erickson, 2008). These durable communities of cells are more resistant to removal and inactivation than free living planktonic cells. Conventional antimicrobial chemical treatments are typically less effective in treating biofilm contamination (Niemira and Solomon, 2005; Ryu and Beuchat, 2005; Langsrud et al., 2016). Biofilms formed by native, nonpathogenic microflora are widely distributed in fresh-produce processing environments, and are known to incorporate human pathogens (Solomon et al., 2005; Jahid and Ha, 2012; Liu et al., 2013).

Cold plasma is an emerging nonthermal antimicrobial process for fresh and fresh-cut fruits and vegetables, nuts and other foods (Niemira, 2012a; Misra et al., 2016). Typically, high voltage electricity is used to ionize gas molecules into a reactive plasma, which can inactivate pathogenic bacteria and viruses (Bermúdez-Aguirre et al., 2013; Lacombe et al., 2017; Min et al., 2017). Cold plasma has also shown specific activity against biofilms, including biofilm-associated Salmonella, Listeria monocytogenes and E. coli biofilms (Brelles-Mariño, 2012; Niemira et al., 2014; Ziuzina et al., 2015). One challenge for cold plasma as an antimicrobial process can be the treatment times required for inactivation, which can vary significantly with the type of cold plasma technology being used. 
The objective of this study is to determine the antimicrobial efficacy of very rapid cold plasma treatments for inactivating E. coli O157:H7 biofilms, and to determine the impact on that efficacy of (a) biofilm age, (b) biofilm distance from the cold plasma emitter head, and (c) electrical generating frequency.

\section{MATERIALS AND METHODS \\ Microorganisms}

All isolates examined were from the culture collection at USDAARS-ERRC. Human outbreak strains of E. coli O157:H7 C9490, ATCC 35150, ATCC 43894. The isolates were maintained in tryptic soy broth (TSB, Difco, Detroit, MI). The method of Niemira and Solomon (Niemira and Solomon, 2005) was used to grow the biofilms, with the following modifications. Sterile TSB $(30 \mathrm{ml})$ was placed in $50 \mathrm{ml}$ incubation tubes, and sterile glass slides $(7.62 \mathrm{~cm}$ by $2.54 \mathrm{~cm})$, were placed therein. $100 \mu \mathrm{l}$ stock solution of each E. coli O157:H7 culture was used to inoculate the tubes. They were then incubated at $37^{\circ} \mathrm{C}$ for 24 , 48 , or $72 \mathrm{~h}$, in order to to allow biofilm formation. Biofilmcoated slides were aseptically removed from the tubes on each day of treatment. To remove unattached cells, the slides were rinsed for $10 \mathrm{~s}$ under a stream of sterile distilled water. The slides were then placed in a biohood and allowed to air dry $10 \mathrm{~min}$ before cold plasma treatment. As an untreated control, a separate slide was similarly air dried, held, and subjected to recovery and enumeration (described below) on each day).

\section{Cold Plasma Treatment}

The cold plasma equipment used in this study was a Dyne-AMite HP (Enercon Corp., Menomonee Falls, WI), modified to allow for variation of the electrical pulse frequency, and described previously (Niemira, 2012b; Niemira et al., 2014). Briefly, this AC plasma jet device is based on a form of gliding arc plasma (Figure 1). Across the $1 \mathrm{~cm}$ gap between two shaped electrodes, an ionizing potential is established, generating a plasma arc. A flow of feed gas (dried air) at 60 psi drives the plasma arc outward from the surrounding Teflon cowling, expanding and cooling it. Varying the pulse frequency is known to be a factor in the antimicrobial efficacy of cold plasma (Alkawareek et al., 2012). Frequencies ranging from 23 to $48 \mathrm{kHz}$ were evaluated, with power consumption of 522 to $549 \mathrm{~W}$.

At each electrical frequency, the glass slides coated with E. coli $\mathrm{O} 157: \mathrm{H7}$ biofilms of each maturity level were placed on a mini-conveyor belt (Dorner Mfg., Hartland, WI) and exposed to cold plasma for 5,10 , or $15 \mathrm{~s}$ at distances from the plasma jet emitter head of 5 or $7.5 \mathrm{~cm}$. Varying the speed of the conveyor belt was the method by which the time of exposure under the cold plasma emitter head for each side of the glass slide was controlled by. The separations were chosen to place the biofilms within the zones of "active" plasma $(5 \mathrm{~cm})$ or "quenched" plasma $(7.5 \mathrm{~cm})$, as previously described (Niemira et al., 2014).

\section{Recovery and Enumeration}

After treatment, to detach and recover cells from the surface of the glass, the slides were vigorously shaken for $60 \mathrm{~s}$ in $10 \mathrm{ml}$

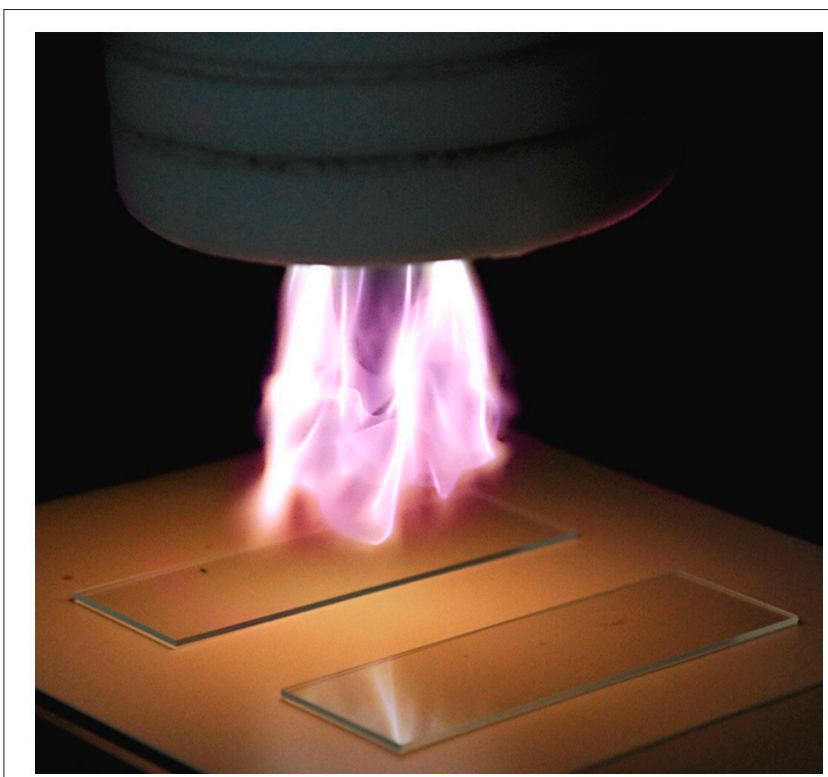

FIGURE 1 | Cold plasma apparatus used in this study, demonstrating application to glass slides. Feed gas is atmospheric air. (Photo: Joseph Sites, USDA-ARS).

buffered peptone water (BPW) in a fresh $50 \mathrm{ml}$ capped tube., Cells were then serially diluted in BPW and spread plated onto TSA, according to the method of Niemira and Solomon (Niemira and Solomon, 2005). Enumerations had a minimum detection limit of $2.0 \log \mathrm{cfu} \mathrm{ml} \mathrm{m}^{-1}$. The plates were inverted, incubated at $37^{\circ} \mathrm{C}$, $24 \mathrm{~h}$, and enumerated with an automated plate counter. Log cfu $\mathrm{ml}^{-1}$ reduction were based on comparison to untreated control slides. Experiments performed in duplicate, with three plates per treatment, per replication.

\section{Temperature Monitoring}

To determine the contribution of heating for any antimicrobial reductions obtained, an infrared camera (Fluke Ti32, Evrett, WA, USA) was used to establish the temperature of glass slides treated with the specific combinations of spacing and times used in this study. Model slides were treaated with cold plasma and thermographs recorded, with separate temperature readings for each pixel in the image. The area of the slide was selected using the camera software and the minimum, maximum, and average temperatures were obtained for each treatment combination. The maximum values were pooled and subjected to statistical analysis.

\section{Statistics}

For each combination of biofilm age, frequency, time and distance, values for reduction from control were pooled ( $n=9$ per combination) and means compared with analysis of variance (ANOVA) and the Student-Newman-Keuls test to establish the significance of the various treatment factors, singly and in combination (SigmaPlot 11, Systat Software, Chicago, IL). 


\section{RESULTS AND DISCUSSION}

Foodborne contamination associated with E. coli O157:H7, Salmonella, L. monocytogenes, and other pathogens continues to be a serious concern (Sivapalasingam et al., 2004; U.S. Food Drug Admin (FDA), 2009; Cevallos-Cevallos et al., 2012), with costs in the U.S. estimated to be between $\$ 34$ and $\$ 39$ billion (Institute of Food Technologists, 2004; Scharff, 2010). Elimination of these pathogens from foods and food contact surfaces is a primary goal of sanitation programs and antimicrobial interventions. Cold plasma has recently gained attention as a potential tool for the food processing industry (Niemira, 2012a; Lacombe et al., 2017; Min et al., 2017). More specifically for the application of cold plasma to biofilms, a wide range of plasma technologies are currently being investigated which range in efficacy, speed of operation, feed gas composition, configuration, etc. (Tran et al., 2008; Brelles-Mariño, 2012). All short-duration treatments with cold plasma significantly reduced E. coli O157:H7 biofilms. Age of the biofilm was not a significant factor, as for each combination of time, distance and frequency, biofilms of $24 \mathrm{~h}$ (Figure 2), $48 \mathrm{~h}$ (Figure 3), and $72 \mathrm{~h}$ (Figure 4) maturity showed responses which were not notably different from each other. For $5 \mathrm{~cm}$ spacing treatments, reductions generally increased with exposure time, with reductions ranged from 0.63 to $1.41 \log \mathrm{cfu} \mathrm{ml}^{-1}(5 \mathrm{~s})$, 1.42 to $2.57 \mathrm{cfu} / \mathrm{ml}(10 \mathrm{~s})$, and 1.65 to $3.29 \log \mathrm{cfu} \mathrm{ml}^{-1}$ (15 s) (Figures 1-3). At this spacing, reductions after $5 \mathrm{~s}$ were lower than those of 10 or $15 \mathrm{~s}$ for almost all pulse frequencies tested. For pulse frequencies of $38 \mathrm{kHz}$ and lower, reductions after $15 \mathrm{~s}$ exceeded those after $10 \mathrm{~s}$. For pulse frequencies of $42 \mathrm{kHz}$ and higher, 10 and $15 \mathrm{~s}$ treatments gave equivalent reductions.

Increasing the separation distance to $7.5 \mathrm{~cm}$ generally reduced the efficacy of the 5 and 10 s treatments, with reductions of $0.59-$ $0.96 \log \mathrm{cfu} / \mathrm{ml}$ and $1.38-2.13 \log \mathrm{cfu} \mathrm{ml}^{-1}$, respectively. For the $15 \mathrm{~s}$ treatment at $7.5 \mathrm{~cm}$, the range of reductions was narrowed to 2.02-3.29 $\log \mathrm{cfu} \mathrm{ml} \mathrm{m}^{-1}$, but the maximal reduction obtained was comparable to that obtained at $5 \mathrm{~cm}$. Unlike with the $5 \mathrm{~cm}$ spacing, there was a clear association of increasing antimicrobial efficacy with increasing time of treatment. For both 5 and $7.5 \mathrm{~cm}$ spacing, the frequencies varied for which the greatest or lowest antimicrobial effects were observed for each treatment time. Untreated controls gave plate counts of 5.8-6.4 log $\mathrm{cfu} \mathrm{ml} \mathrm{m}^{-1}$ across all biofilm ages examined.

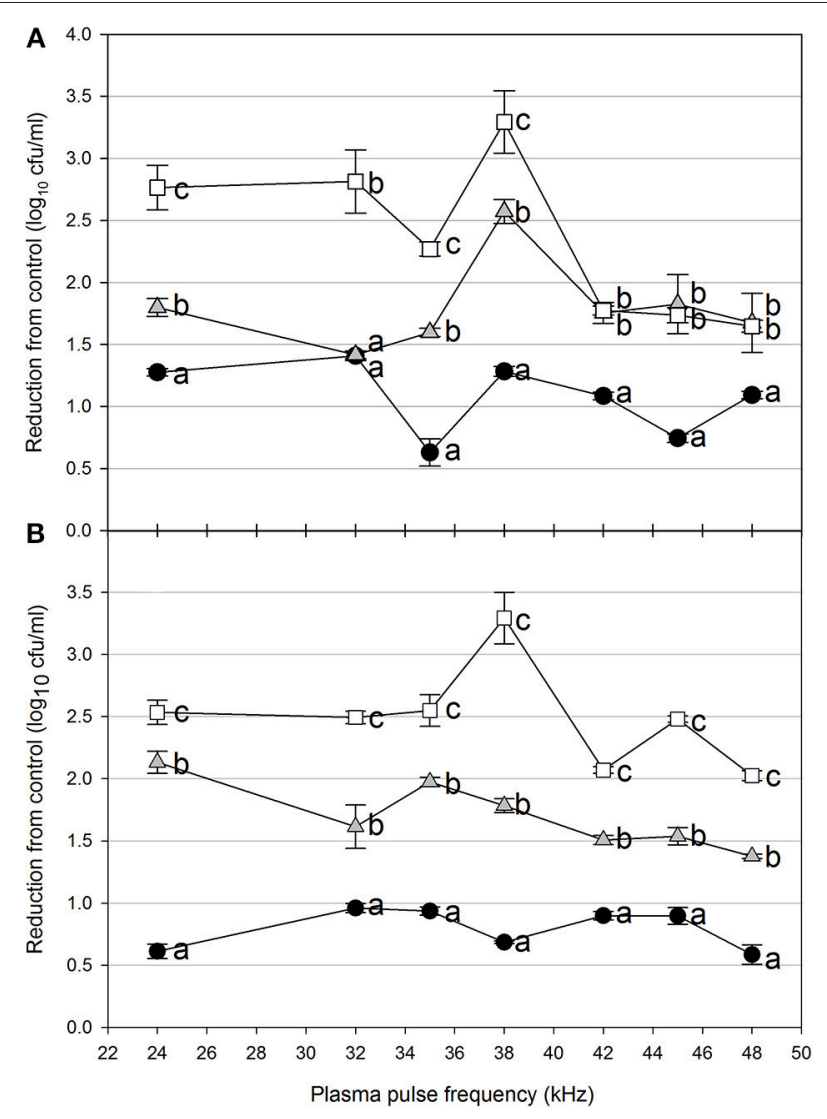

FIGURE 2 | Cold plasma reduction of $24 \mathrm{~h}$ biofilms of E. coli O157:H7, treated for $5 \mathrm{~s}$ (black circle), $10 \mathrm{~s}$ (gray triangle), or $15 \mathrm{~s}$ (white square). Treated surfaces were $5 \mathrm{~cm}$ (A) or $7.5 \mathrm{~cm}$ (B) from the plasma emitter head. Within each plasma pulse frequency $(\mathrm{kHz})$, reductions with the same letter are not significantly different $(P<0.05$, ANOVA). Bars indicate standard error.

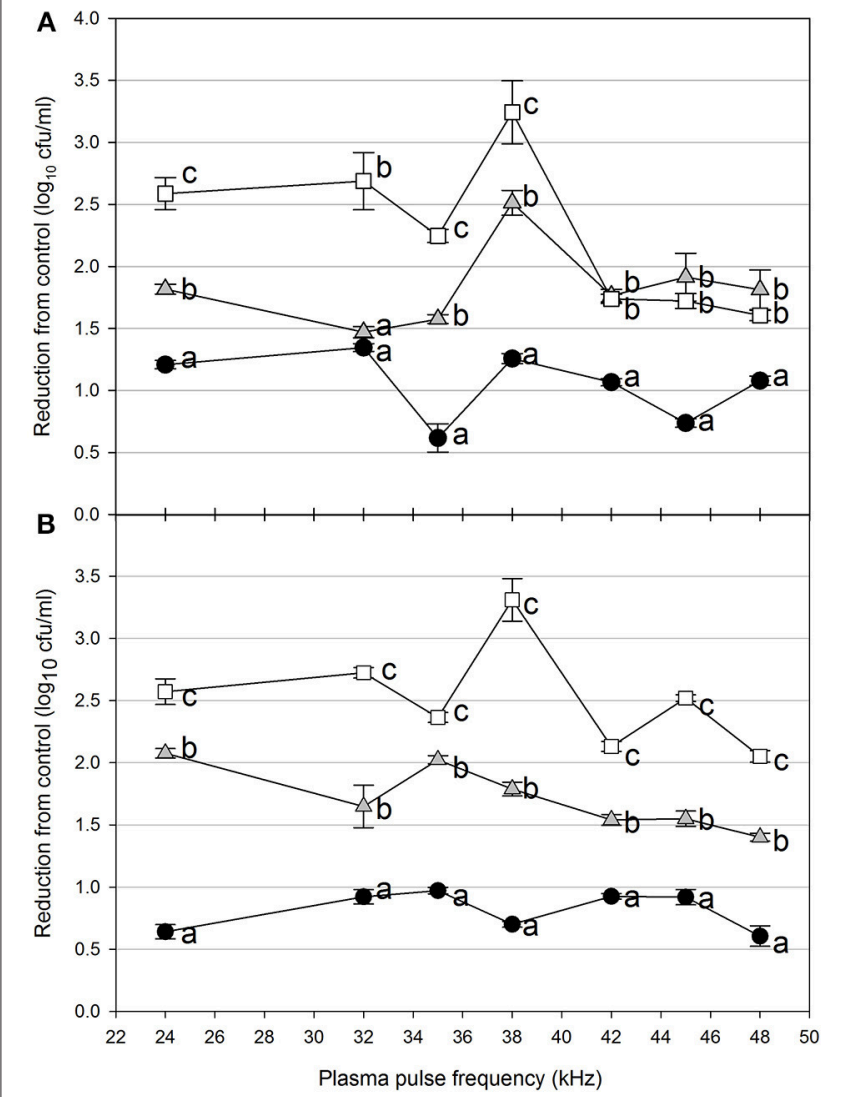

FIGURE 3 | Cold plasma reduction of 48 h biofilms of E. coli O157:H7, treated for $5 \mathrm{~s}$ (black circle), $10 \mathrm{~s}$ (gray triangle), or $15 \mathrm{~s}$ (white square). Treated surfaces were $5 \mathrm{~cm}$ (A) or $7.5 \mathrm{~cm}$ (B) from the plasma emitter head. Within each plasma pulse frequency $(\mathrm{kHz})$, reductions with the same letter are not significantly different $(P<0.05$, ANOVA). Bars indicate standard error. 


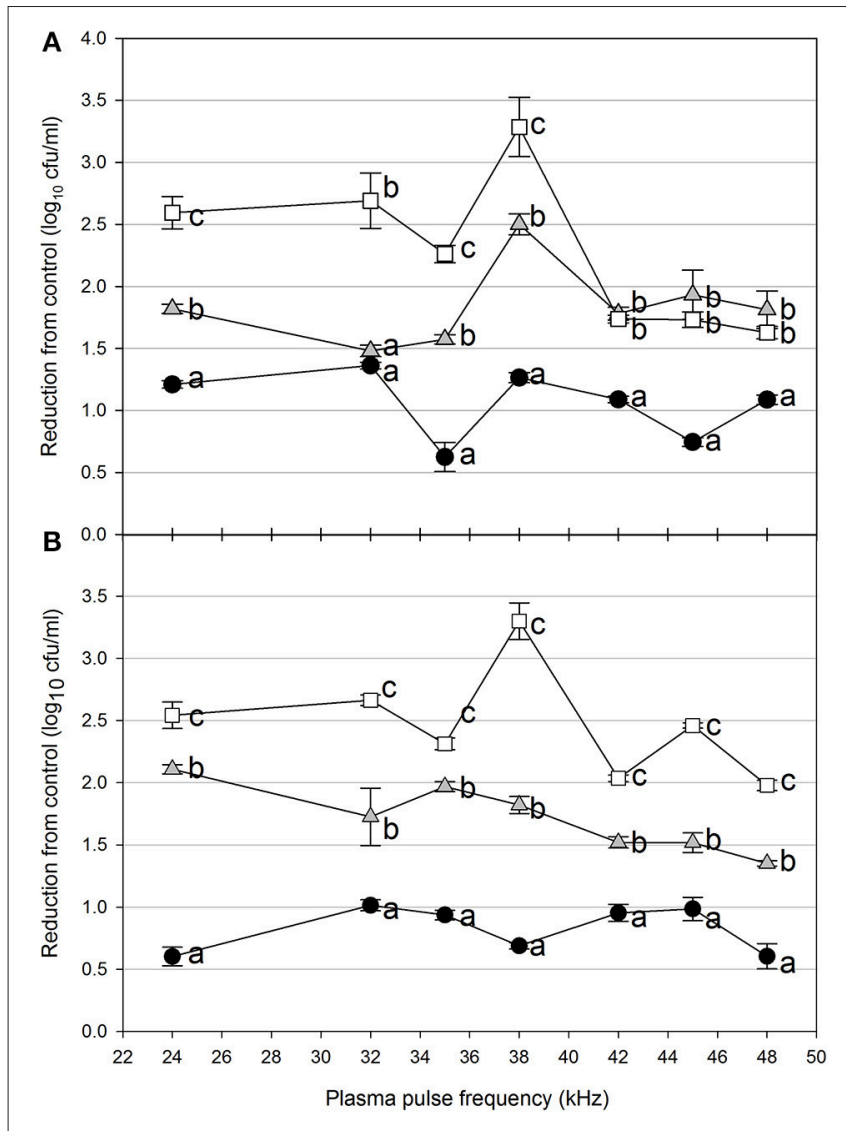

FIGURE 4 | Cold plasma reduction of $72 \mathrm{~h}$ biofilms of $E$. coli $0157: \mathrm{H} 7$, treated for $5 \mathrm{~s}$ (black circle), $10 \mathrm{~s}$ (gray triangle), or $15 \mathrm{~s}$ (white square). Treated surfaces were $5 \mathrm{~cm}$ (A) or $7.5 \mathrm{~cm}$ (B) from the plasma emitter head. Within each plasma pulse frequency $(\mathrm{kHz})$, reductions with the same letter are not significantly different $(P<0.05$, ANOVA). Bars indicate standard error.

The antimicrobial effects of the cold plasma treatment were not caused by heat. Thermal imaging analysis showed that none of the treatments operated at the $58-60^{\circ} \mathrm{C}$ minimum temperatures required for thermal kill (Stringer et al., 2000; Table 1). Following cold plasma treatment, maximum temperatures across the treated areas of the slides were $35.0-45.7^{\circ} \mathrm{C}$ for the $5 \mathrm{~cm}$ spacing, and $38.1-53.4^{\circ} \mathrm{C}$ for the $7.5 \mathrm{~cm}$ spacing (Figure 5). Therefore, the mechanisms of kill observed with cold plasma are chemical in nature. It is possible that longer treatment times beyond $15 \mathrm{~s}$ would engender thermal effects. While temperature control measures were not used in this study, other studies have used meaures such as forced air cooling to control untoward thermal effects (Lacombe et al., 2017).

In this study, a cold plasma jet achieved reductions of $E$. coli O157:H7 biofilms of up to $3.29 \mathrm{log} \mathrm{cfu} \mathrm{m}^{-1}$ with a treatment time of $15 \mathrm{~s}$ on a model food contact surface. Efficacy was influenced by the pulse frequency of the electricity used to generate the cold plasma, by the spacing of the emitter head with respect to the E. coli O157:H7 biofilms, and by the treatment time. This cold plasma treatment apparatus used using a model conveyor belt system, with treatment times chosen to be consistent with
TABLE 1 | Calculated D10 values for cold plasma inactivation of Escherichia coli 0157:H7 biofilms.

\begin{tabular}{|c|c|c|c|c|}
\hline $\begin{array}{l}\text { Electrode } \\
\text { spacing } \\
\text { [cm] }\end{array}$ & $\begin{array}{c}\text { Treatment } \\
\text { time [s] }\end{array}$ & $\begin{array}{c}\text { Slide } \\
\text { temperature } \\
{\left[{ }^{\circ} \mathrm{C}\right]^{\mathrm{a}}}\end{array}$ & $\begin{array}{l}\text { Inactivation } \\
\text { range [log } \\
\text { cfu ml-1 } \text { mb }^{\text {b }}\end{array}$ & $\begin{array}{c}\text { D10 range } \\
\text { [s] }\end{array}$ \\
\hline \multirow[t]{4}{*}{5} & 5 & $35.0 \mathrm{~A}$ & $0.63-1.41$ & $7.94-3.55$ \\
\hline & 10 & $45.7 \mathrm{~B}$ & $1.42-2.57$ & $7.04-3.89$ \\
\hline & 15 & $44.6 \mathrm{BC}$ & $1.65-3.29$ & $9.09-4.56$ \\
\hline & Average & & & $8.02-4.00$ \\
\hline \multirow[t]{4}{*}{7.5} & 5 & $38.1 \mathrm{AC}$ & $0.59-0.96$ & $8.47-5.21$ \\
\hline & 10 & 46.6 BD & $1.38-2.13$ & $7.25-4.69$ \\
\hline & 15 & $53.4 \mathrm{D}$ & $2.02-3.29$ & $7.43-4.56$ \\
\hline & Average & & & $7.72-4.82$ \\
\hline
\end{tabular}

a Maximum temperatures obtained on treated slides. Values with the same letter are not statistically different $(P<0.05$, ANOVA, Tukey).

${ }^{b}$ For each time of exposure, the lowest and highest levels of microbial inactivation observed across a pulse frequency range of $24-48 \mathrm{kHz}$.

commercial practice. The ranges of reductions obtained at $5 \mathrm{~cm}$ were somewhat wider than those observed at the $7.5 \mathrm{~cm}$ spacing. At the wider spacing, reductions were generally reduced for the 5 and $10 \mathrm{~s}$ treatments, but not for the $15 \mathrm{~s}$ treatment.

A clear association of treatment time with antimicrobial efficacy was observed for the $7.5 \mathrm{~cm}$ spacing at all pulse frequencies. At the closer $5 \mathrm{~cm}$ spacing, this association was generally observed for pulse frequencies of $38 \mathrm{kHz}$ and lower. At pulse frequencies of $42 \mathrm{kHz}$ and higher, the 10 and $15 \mathrm{~s}$ treatments did not differ in their efficacy. The specific pulse frequencies at which maximal (or minimal) pathogen inactivation occurred varied, based on emitter head spacing and time of treatment. Calculation of D10 values based on the minimal and maximal inactivation for each treatment time showed that the spacing configuration had a modest effect (Table 1). The D10 values calculated from the $\log \mathrm{cfu} \mathrm{m}^{-1}$ inactivations at the minimally effective pulse frequencies were $7.04-9.09 \mathrm{~s}$ at $5 \mathrm{~cm}$ and $7.25-$ $8.47 \mathrm{~s}$ at $7.5 \mathrm{~cm}$. For the maximally effective pulse frequencies, D10s were shorter, were $3.55-4.56 \mathrm{~s}$ at $5 \mathrm{~cm}$ and $4.56-5.21 \mathrm{~s}$ at $7.5 \mathrm{~cm}$ (Table 1). There was in general less variation in antimicrobial efficacy among the pulse frequencies at the wider electrode spacing.

The development of a general predictive statement regarding the relationship of pulse frequency with antimicrobial efficacy is complex. In previous studies using a plasma system based on a $99.5 \%$ helium, $0.05 \%$ oxygen feed gas, Alkawareek and others (Alkawareek et al., 2012), a $15 \mathrm{~s}$ treatment reduced Pseudomonas aeruginosa biofilms by $0.8 \mathrm{cfu} / \mathrm{ml}$ at a pulse frequency of $20 \mathrm{kHz}$ and by $1.6 \log \mathrm{cfu} / \mathrm{ml}$ at $40 \mathrm{kHz}$. In contrast, Niemira et al. (Niemira et al., 2014), using the same equipment and feed gas (air) used in the present study, showed no clear association of antimicrobial efficacy against Salmonella biofilms for pulse frequencies ranging from 24 to $48 \mathrm{kHz}$. Direct comparisons between studies using different biofilm forming organisms, or that rely on different cold plasma feed gas composition, are more suggestive than conclusive. These results highlight the need for further research into the effects of pulse frequency within the 

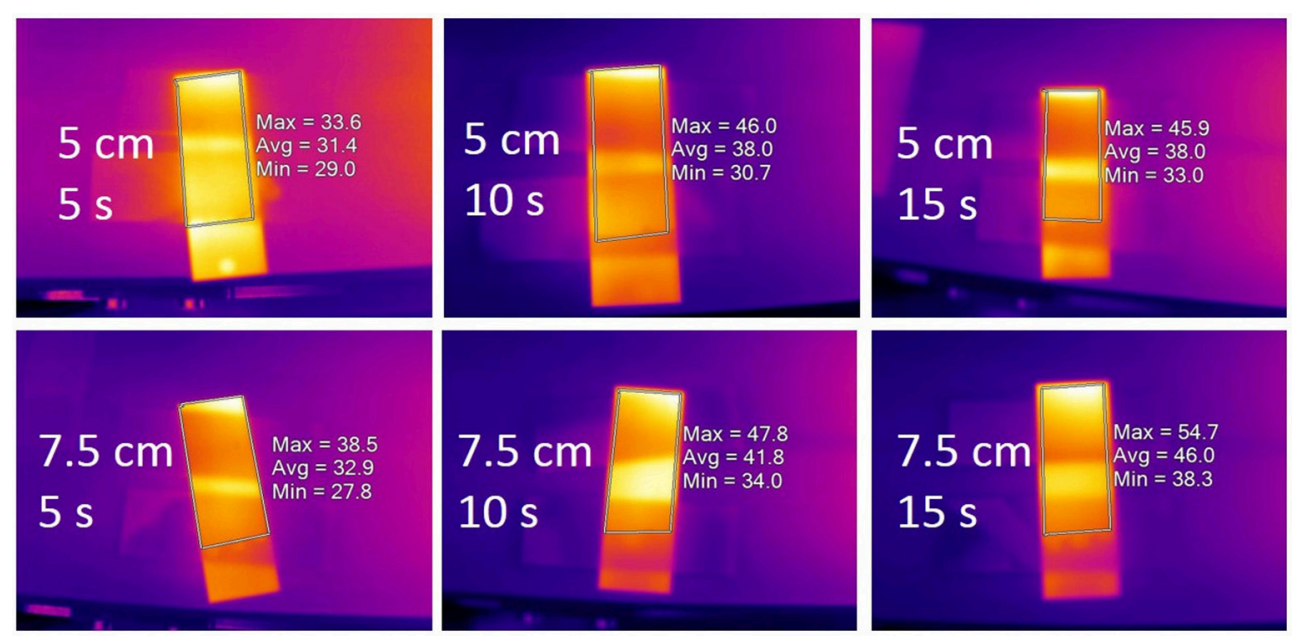

FIGURE 5 | Composite thermograph of cold plasma-treated slides. Inset labels indicate time of treatment (5, 10, or 15 s) and gap spacing (5 or $7.5 \mathrm{~cm})$. Minimum, maximum and average temperatures are from the selected image areas representing the treated slides.

context of different equipment designs and treatment operating conditions.

The maturity of the biofilm did not significantly influence the antimicrobial efficacy of the cold plasma process. The E. coli O157:H7 biofilms of 24,48 , and $72 \mathrm{~h}$ maturity responded to treatment in similar ways at all frequencies, treatment times and distances. This is consistent with a previous study using this cold plasma equipment applied to Salmonella biofilms (Niemira et al., 2014), but stands in contrast to work with other antimicrobial treatments. In studies of Salmonella (Niemira and Solomon, 2005), E. coli O157:H7 (Niemira, 2007) as well as L. monocytogenes and L. innocua (Niemira, 2010), the biofilms age, growth temperatures and culture conditions led to varying responses to nonthermal interventions. While the biofilms in this study were single species biofilms grown on inert surfaces, the complex, multi-species biofilms grown on the surfaces of fruits and vegetables will necessarily interact with the substrate in different ways as the biofilms grow and mature. This will influence their response to antimicrobial interventions, including cold plasma. In this study, the biofilms herein were dried for $10 \mathrm{~min}$ in a flow of moving air. Although they were thus made more robust and durable, these biofilms were reduced by multiple $\log \mathrm{cfu} / \mathrm{ml}$ without additional sanitizing compounds, physical abrasion, or other augmentations of the intervention. Combination with other, more conventional antimicrobial interventions will likely enhance the cold plasma reductions obtained.

Cold plasma therefore holds potential for treating biofilms of long-standing persistence in the food processing environment. The plasma jet system in this study creates a plume which may be suitable for a variety of food contact surfaces. These could include belts (unitary and flexi-belts), equipment, knives, etc. Further studies with biofilms produced on different materials are ongoing. Also, the response of biofilms grown under different conditions, including using other biofilm cultivation systems such as flow reactors or rotating biofilm reactors (McLean et al., 2004; Liu et al., 2013), will help to further elucidate the modes of action by which cold plasma inactivates these pathogens.

Increasing the spacing between the emitter head and the treated biofilm surface tended to reduce the variation resulting from the pulse frequency. Also, closer spacing was generally more effective at reducing the pathogen, although the maximal reductions observed for the $15 \mathrm{~s}$ treatment time were not affected. The distances chose for this study correspond to a zone $(5 \mathrm{~cm})$ of active plasma and a zone $(7.5 \mathrm{~cm})$ where active plasma has given way to quenched plasma. Active plasma is rich in the most reactive plasma species-radical molecules, free electrons, oxygen singlets, and other very short-lived products of plasma ionization. Interactions within the plasma plume during transit from the high-voltage electrodes to the bacterial target result in the recombination of some of these most reactive species to make the chemical species that predominate in quenched cold plasma: $\mathrm{O}_{3}, \mathrm{H}_{2} \mathrm{O}_{2}, \mathrm{NO}_{\mathrm{X}}$, etc. Because active plasma is the most reactive form of cold plasma, it is expected to have the higher antimicrobial efficacy than quenched plasma. This expectation was seen more clearly in the $5 \mathrm{~s}$ and $10 \mathrm{~s}$ treatments than in the $15 \mathrm{~s}$ treatment. One possibility is that the configuration of this plasma jet (Figure 1) may lead to an induced admixture of surrounding air into the plasma plume, drawn in by Bernoulli effects of the pressurized plasma jet. Further research into the specific chemistries of the plasma, in both the active and quenched zones, will better elucidate the antimicrobial modes of action.

In a study of pathogen biofilms grown directly on produce, lettuce leaves were dip-inoculated in cultures of Salmonella Typhimurium, L. monocytogenes or E. coli, and incubated for up to $48 \mathrm{~h}$ to allow biofilms to form (Ziuzina et al., 2015). These were then packaged and treated with quenched cold plasma. The leaf-associated biofilms showed reductions of up to $5 \mathrm{log}$ cfu $\mathrm{ml}^{-1}$ after a $5 \mathrm{~min}$ treatment. In that study, the efficacy of the 
cold plasma process was dependent on pathogen type, storage conditions, and age of the biofilm. By comparison, the same treatment applied to free-living, planktonic cells, elicited nearly complete reductions in approximately $30 \mathrm{~s}$. This supports the contention that cold plasma can be an effective antimicrobial process for biofilms on actual food products as well as on food contact surfaces. However, impacts on product quality and shelflife will be an essential part of this technology development research.

Optimization of cold plasma as a sanitizing process will require balancing antimicrobial efficacy with the length of treatment. Depending on the type of equipment, the processing conditions, the feed gas used, and other factors, multi-log reductions may be obtained in times ranging from seconds to minutes. This will be a critical aspect of commercialization, as will the potential for combining cold plasma with sanitizing processes that remove organic material (Niemira, 2012a; Misra et al., 2016; Adamovich et al., 2017). Studies examining cold plasma inactivation of contamination on stainless steel, commercially used plastics, conveyor belt materials and other food contact surfaces are ongoing. Also, to adapt cold plasma for the particular conditions of biofilm contamination in the food processing environment and on standard equipment, the response of industrial pathogen isolates should be evaluated in addition to clinical isolates, such as used in this study. It should be noted that in a production environment, organic matter from the fruits and vegetables being processed may be a factor in the efficacy of this type of cold plasma treatment. Food particulates, soluble organic matter, and other organic debris may serve to protect contaminating organisms from the reactive oxygen species and other active plasma chemistries. This will require an optimized approach, e.g. necessitating longer treatment times than the $15 \mathrm{~s}$ examined herein, closer spacing, wider cold plasma treatment heads, higher airflow rates, etc.

The cost of implementation of cold plasma will necessarily be a critical factor in commercialization. The research-scale unit used in this study consumed 522 to $549 \mathrm{~W}$; in comparison, a regular home hair dryer uses $\sim 1,500 \mathrm{~W}$. While cold plasma technology is not yet at a stage where definitive economic answers can be obtained, Niemira (2012a) provided an economic analysis of costs for fixed equipment, energy consumption, consumable supplies, gases and gas mixtures, and other elements. That analysis suggested that a commercial cold plasma system, such

\section{REFERENCES}

Mandrell, R. E. (2009). "Enteric human pathogens associated with fresh produce: sources, transport and ecology," in Microbial Safety of Fresh Produce, eds X. Fan, B. A. Niemira, C. J. Doona, F. E. Feeherry, and R. B Gravani (Ames, IA: Blackwell Publishing), 5-41.

Institute of Food Technologists (2004). Bacteria associated with foodborne diseases. Food Technol. 58, 20-21

U.S. Food Drug Admin (FDA) (2009). Potential for Infiltration, Survival and Growth of Human Pathogens Within Fruits and Vegetables. Available online at: http://www.fda.gov/Food/GuidanceRegulation/ HACCP/ucm082063.htm (Accessed April 19, 2018). as one with the multiple cold plasma emitter heads necessary to treat wide areas of conveyor belts or other equipment in a commercially reasonable time frame, might draw electricity on the order of $90 \mathrm{~kW}$, representing an eletrical cost of $\$ 4500$ per $1,000 \mathrm{~h}$ of operation. This would be on par with some types of commercial-scale equipment used in the food industry, such as lighting, conveyor belt motors, slicers, sorters, etc., and would be considerably less power-intensive than other elements, such as refrigeration systems.

\section{CONCLUSION}

Very short cold plasma treatments significantly inactivated E. coli O157:H7 biofilms, with up to $3.29 \log \mathrm{cfu} \mathrm{ml} l^{-1}$ inactivated after only $15 \mathrm{~s}$ of exposure. Inactivation was not dependent on heat. The response was influenced by cold plasma pulse frequency, and by the gap spacing between plasma emitter and the biofilm surface. Depending on pulse frequency, D10 value for biofilm inactivation averaged 4.00-4.82 $\mathrm{s}$ in the most effective treatments. Increasing biofilm maturity did not significantly alter the antimicrobial efficacy of the process. With further optimization, cold plasma shows promise as a waterless, rapid tool for sanitizing food contact surfaces.

\section{AUTHOR CONTRIBUTIONS}

$\mathrm{BN}$ and GB contributed equally to the execution of the microbiological experiments. JS led the thermal imaging analysis experiments. $\mathrm{BN}$ led the data analysis and manuscript writing.

\section{FUNDING}

This work was funded under Research Project 41420-020 of the US Department of Agriculture, Agricultural Research Service.

\section{ACKNOWLEDGMENTS}

The authors would like to thank Ms. Janysha Taylor for her expert technical assistance. Mention of trade names or commercial products in this publication is solely for the purpose of providing specific information and does not imply recommendation or endorsement by the U.S. Department of Agriculture. The USDA is an equal opportunity employer.
Adamovich, I., Baalrud, S. D., Bogaerts, A., Bruggeman, P. J., Cappelli, M., Colombo, V., et al. (2017). The 2017 Plasma roadmap: low temperature plasma science and technology. J. Phys. D Appl. Phys. 50, 1-5. doi: 10.1088/1361-6463/aa76f5

Alkawareek, M. Y., Algwari, Q. T., Laverty, G., Gorman, S. P., Graham, W. G., O'Connell, D., et al. (2012). Eradication of Pseudomonas aeruginosa biofilms by atmospheric pressure non-thermal plasma. PLoS ONE 7:e44289. doi: 10.1371/journal.pone.0044289

Bermúdez-Aguirre, D., Wemlinger, E., Pedrow, P., Barbosa-Cánovas, G., and Garcia-Perez, M. (2013). Effect of atmospheric pressure cold plasma (APCP) on the inactivation of Escherichia coli in fresh produce. Food Control 34, 149-157. doi: 10.1016/j.foodcont.2013.04.022 
Brelles-Mariño, G. (2012). Challenges in biofilm inactivation: the use of cold plasma as a new approach. J. Bioprocess Biotechniques 2:e107. doi: 10.4172/2155-9821.1000e107

Cevallos-Cevallos, J. M., Gu, G., Danyluk, M. D., Dufault, N. S., and van Bruggen, A. H. (2012). Salmonella can reach tomato fruits on plants exposed to aerosols formed by rain. Int. J. Food Micro. 158, 140-146. doi: 10.1016/j.ijfoodmicro.2012.07.009

Doyle, M. P., and Erickson, M. C. (2008). Summer meeting 2007-the problems with fresh produce: an overview. J. Appl. Microbiol. 105, 317-330. doi: $10.1111 / j .1365-2672.2008 .03746 . x$

Jahid, I. K., and Ha, S. D. (2012). A review of microbial biofilms of produce: future challenge to food safety. Food. Sci. Biotech. 21, 299-316. doi: 10.1007/s10068-012-0041-1

Lacombe, A., Niemira, B. A., Gurtler, J. B., Sites, J., Boyd, G., Kingsley, D. H., et al. (2017). Nonthermal inactivation of norovirus surrogates on blueberries using atmospheric cold plasma. Food Micro. 63, 1-5 doi: 10.1016/j.fm.2016.10.030

Langsrud, S., Moen, B., Møretrø, T., Løype, M., and Heir, E. (2016). Microbial dynamics in mixed culture biofilms of bacteria surviving sanitation of conveyor belts in salmon-processing plants. J. Appl. Micro. 120, 366-378. doi: $10.1111 /$ jam. 13013

Liu, N. T., Lefcourt, A. M., Nou, X., Shelton, D. R., Zhang, G., and Lo, Y. M. (2013). Native microflora in fresh-cut produce processing plants and their potentials for biofilm formation. J. Food Prot. 5, 827-832. doi: 10.4315/0362-028X.JFP-12-433

McLean, R. J. C., Bates, C. L., Barnes, M. B., McGowin, C. L., and Aron, G. M. (2004). "Methods of studying biofilms," in Microbial Biofilms, eds M. Ghannoum and G. A. O'Toole (Washington, DC: ASM Press), 379-413.

Min, S. C., Roh, S. H., Niemira, B. A., Boyd, G., Sites, J. E., Uknalis, J., et al. (2017). In-package inhibition of E. coli O157:H7 on bulk Romaine lettuce using cold plasma. Food Micro. 65, 1-6. doi: 10.1016/j.fm.2017.01.010

Misra, N. N., Schluter, O. K., and Cullen, P. J. (2016). Cold Plasma in Food and Agriculture. New York, NY: Academic Press.

Niemira, B. A. (2007). Irradiation sensitivity of planktonic and biofilm-associated Escherichia coli $\mathrm{O} 157: \mathrm{H} 7$ isolates is influenced by culture conditions. Appl. Environ. Microbiol. 73, 3239-3244. doi: 10.1128/AEM.02764-06

Niemira, B. A. (2010). Influence of growth temperature on irradiation sensitivity of planktonic and biofilm-associated Listeria monocytogenes and L. innocua. Food Bioprocess Technol. 3, 257-264. doi: 10.1007/s11947-0080079-5

Niemira, B. A. (2012a). Cold Plasma Decontamination of Foods. Annu. Rev. Food Sci. Technol. 2012, 125-142. doi: 10.1146/annurev-food-022811-101132

Niemira, B. A. (2012b). Cold plasma reduction of Salmonella and Escherichia coli $\mathrm{O} 157: \mathrm{H7}$ on almonds using ambient pressure gases. J. Food Sci. 77, M171-M175. doi: 10.1111/j.1750-3841.2011.02594.x

Niemira, B. A., Boyd, G., and Sites, J. (2014). Cold plasma rapid decontamination of food contact surfaces contaminated with Salmonella biofilms. J. Food Sci. 79, M917-M922. doi: 10.1111/1750-3841.12379
Niemira, B. A., and Solomon, E. B. (2005). Sensitivity of planktonic and biofilmassociated Salmonella to ionizing radiation. Appl. Environ. Microbiol. 71, 2732-2736. doi: 10.1128/AEM.71.5.2732-2736.2005

Reisner, A., Krogfelt, K. A., Klein, B. M., Zechner, E. L., and Molin, S. (2006). In vitro biofilm formation of commensal and pathogenic Escherichia coli strains: impact of environmental and genetic factors. J. Bact. 188, 3572-3581. doi: $10.1128 / J B .188 .10 .3572-3581.2006$

Ryu, J. H., and Beuchat, L. R. (2005). Biofilm formation by Escherichia coli $\mathrm{O} 157: \mathrm{H7}$ on stainless steel: effect of exopolysaccharide and curli production on its resistance to chlorine. Appl. Environ. Micro. 71, 247-254. doi: 10.1128/AEM.71.1.247-254.2005

Scharff, R. L. (2010). Health-Related Costs From Foodborne Illness in the United States. Produce Safety Project, Available online at: http://www. pewtrusts.org/en/research-and-analysis/reports/0001/01/01/healthrelatedcosts-from-foodborne-illness-in-the-united-states (Accessed April 19, 2018).

Sivapalasingam, S., Friedman, C. R., Cohen, L., and Tauxe, R. V. (2004). Fresh produce: a growing cause of outbreaks of foodborne illness in the United States, 1973 through 1997. J. Food Prot. 67, 2342-2353. doi: 10.4315/0362-028X-67.10.2342

Solomon, E. B., Niemira, B. A., Sapers, G. M., and Annous, B. A. (2005). Biofilm formation, cellulose production and curli biosynthesis by Salmonella spp. originating from produce, animal, clinical sources. J. Food. Prot. 68, 906-912. doi: 10.4315/0362-028X-68.5.906

Stringer, S. C., George, S. M., and Peck, M. W. (2000). Thermal inactivation of Escherichia coli O157:H7. J. Appl. Micro. Symp. Suppl. 88, 795-895. doi: 10.1111/j.1365-2672.2000.tb05335.x

Tran, N., Amidi, M., and Sanguansri, P. (2008). Cool plasma for large scale chemical-free microbial inactivation of surfaces. Food Aust. 60, 344-347.

Ziuzina, D., Han, L., Cullen, P. J., and Bourke, P. (2015). Cold plasma inactivation of internalised bacteria and biofilms for Salmonella enterica serovar Typhimurium, Listeria monocytogenes and Escherichia coli. Int. J. Food Micro. 210, 53-61. doi: 10.1016/j.ijfoodmicro.2015.05.019

Ziuzina, D., Patil, S., Cullen, P. J., Keener, K. M., and Bourke, P. (2014), Atmospheric cold plasma inactivation of Escherichia coli, Salmonella enterica serovar Typhimurium and Listeria monocytogenes inoculated on fresh produce. Food Micro. 42, 109-116. doi: 10.1016/j.fm.2014.02.007

Conflict of Interest Statement: The authors declare that the research was conducted in the absence of any commercial or financial relationships that could be construed as a potential conflict of interest.

Copyright (c) 2018 Niemira, Boyd and Sites. This is an open-access article distributed under the terms of the Creative Commons Attribution License (CC BY). The use, distribution or reproduction in other forums is permitted, provided the original author(s) and the copyright owner(s) are credited and that the original publication in this journal is cited, in accordance with accepted academic practice. No use, distribution or reproduction is permitted which does not comply with these terms. 